\title{
Tenascin-c mediated vasculogenic mimicry formation via regulation of MMP2/MMP9 in glioma
}

\author{
Hai-ping Cai', Jing Wang ${ }^{1}$, Shao-yan $\mathrm{Xi}^{2}$, Xiang-rong $\mathrm{Ni}^{1}$, Yin-sheng Chen', Yan-jiao Yu', Zi-wen Cen', Zhi-hui Yu', \\ Fu-rong Chen ${ }^{1}$, Cheng-cheng Guo ${ }^{1}$, Ji Zhang ${ }^{1}$, Chao Ke ${ }^{1}$, Jian Wang ${ }^{1}$ and Zhong-ping Chen ${ }^{1}$
}

\begin{abstract}
Vasculogenic mimicry (VM), the formation of vessel-like structures by highly invasive tumor cells, has been considered one of several mechanisms responsible for the failure of anti-angiogenesis therapy in glioma patients. Therefore, inhibiting VM formation might be an effective therapeutic method to antagonize the angiogenesis resistance. This study aimed to show that an extracellular protein called Tenascin-c (TNC) is involved in VM formation and that TNC knockdown inhibits VM in glioma. TNC was upregulated with an increase in glioma grade. TNC and VM formation are potential independent predictors of survival of glioma patients. TNC upregulation was correlated with VM formation, and exogenous TNC stimulated VM formation. Furthermore, TNC knockdown significantly suppressed VM formation and proliferation in glioma cells in vitro and in vivo, with a reduction in cellular invasiveness and migration. Mechanistically, TNC knockdown decreased Akt phosphorylation at $\mathrm{Ser}^{473}$ and $\mathrm{Thr}^{308}$ and subsequently downregulated matrix metalloproteinase 2 and 9, both of which are important proteins associated with VM formation and migration. Our results indicate that TNC plays an important role in VM formation in glioma, suggesting that TNC is a potential therapeutic target for anti-angiogenesis therapy for glioma.
\end{abstract}

\section{Introduction}

Glioma is the most common primary malignancy of the central nervous system. According to the WHO classification, gliomas are classified into four grades (grades I-IV), grades III and IV glioma are high-grade gliomas with poor prognosis. Excessive angiogenesis and adequate blood supply result in rapid proliferation and invasion in high-grade gliomas. Therefore, targeting angiogenesis may yield efficient anti-glioma therapies ${ }^{1}$. Receptor tyrosine kinase inhibitors (RTKIs) and recombinant humanized monoclonal antibodies have been widely studied in

\footnotetext{
Correspondence: Zhong-ping Chen (chenzhp@sysucc.org.cn)

'Department of Neurosurgery/Neuro-oncology, Sun Yat-sen University Cancer Center; State Key Laboratory of Oncology in South China; Collaborative Innovation Center for Cancer Medicine, Guangzhou, Guangdong 510060, P.R. China

${ }^{2}$ Department of Pathology, Sun Yat-sen University Cancer Center; State Key Laboratory of Oncology in South China; Collaborative Innovation Center for Cancer Medicine, Guangzhou, Guangdong 510060, P.R. China These authors contributed equally: Hai-ping Cai, Jing Wang, Shao-yan Xi Edited by I. Amelio
}

various cancers ${ }^{2}$. Bevacizumab (trade name Avastin) slightly contributed to progression-free survival (PFS) but not overall survival (OS) in glioma patients ${ }^{3}$. Several preclinical studies speculate that vasculogenic mimicry (VM) contributes to anti-angiogenesis therapeutic resistance $^{4-6}$.

Structural features of VM were first reported by Maniotis et al. in 1999 as a phenomenon wherein aggressive tumor cells mimic vascular endothelial cells to form embryonic vasculogenic networks enriched in extracellular matrix (ECM) components, through which blood cells can be transported ${ }^{7}$. VM occurs in numerous solid tumors, including melanoma, head and neck carcinoma, breast cancer, and hepatocellular carcinoma ${ }^{8-12}$. We previously reported VM in glioma in $2005^{13}$. Further studies reported that VM promotes tumor cell invasion and migration, predicting poor clinical outcomes ${ }^{14,15}$.

Dynamic interactions among tumor cells, stromal cells, and the ECM is critical for glioma progression. Overexpression of Laminin-411 correlated with shorter

\section{(c) The Author(s) 2019}

(c) (i) Open Access This article is licensed under a Creative Commons Attribution 4.0 International License, which permits use, sharing, adaptation, distribution and reproduction cc) in any medium or format, as long as you give appropriate credit to the original author(s) and the source, provide a link to the Creative Commons license, and indicate if changes were made. The images or other third party material in this article are included in the article's Creative Commons license, unless indicated otherwise in a credit line to the material. If material is not included in the article's Creative Commons license and your intended use is not permitted by statutory regulation or exceeds the permitted use, you will need to obtain permission directly from the copyright holder. To view a copy of this license, visit http://creativecommons.org/licenses/by/4.0/. 
survival of GBM patients and its depletion increased survival of host animals ${ }^{16}$. Integrins involve in the activation of transforming growth factor- $\beta$ and promote invasiveness, angiogenesis, and maintains cancer cell stemness ${ }^{17}$. Similarly, tenascin-c (TNC), an ECM protein, is overexpressed under pathological conditions, such as injury and inflammation and in tumors ${ }^{18,19}$. TNC supports tumor cell proliferation and migration and correlates with a shorter disease-free time in glioma ${ }^{20}$. It was reported that TNC promoted glioma cell invasion and inhibited tumor proliferation ${ }^{21}$. TNC promoted growth of human brain tumor-initiating cells by activating $\mathrm{NOTCH}$ signaling $^{22}$. TNC plays a proangiogenic role in proliferative diabetic retinopathy ${ }^{23}$; however, it is unclear whether TNC is involved in VM formation in glioma. This study aimed to investigate the role of TNC in VM formation and the effect of TNC knockdown on VM in glioma.

\section{Results}

TNC was upregulated with an increase in the pathological grade and VM formation in glioma

TNC expression was quantified in glioma cells via IHC staining on a tissue microarray containing 229 patient samples $(12,81,72$, and 64 cases of grade I, II, III, and IV glioma, respectively). TNC was significantly upregulated in high-grade glioma rather than in low-grade glioma (Fig. 1a and Supplementary Table 1) and was significantly correlated with a poor prognosis $(p<0.0001$, Fig. 1b), concurrent with the results of the Sun Brain Statistics cohort in the ONCOMINE database showing the upregulation of TNC mRNA with an increase in glioma grade (Fig. 1c). Further, analysis of the association between TNC mRNA levels and patient prognosis based on a TCGA brain statistics dataset $(n=413)$ revealed that high TNC mRNA levels were associated with a poor prognosis compared to low TNC mRNA levels (Fig. 1d). Thereafter, we assessed TNC expression, VM vessels (CD31-negative, PAS-positive), and endothelial vessels (CD31-positive, PAS-positive) in $50 \mathrm{GBM}$ samples. Images of negative TNC staining, positive TNC staining, and the typical morphology of VM (red arrow) and endothelial vessels (black arrow) are shown in Fig. 1e. Our results show that $34 \%$ samples (17/50, Table 1) were VM-positive, $54 \%$ samples (27/50, Table 2) were TNC-positive, and $88 \%$ $(15 / 17)$ of VM-positive samples were TNC-positive (Fig. 1e, pink arrow, Table 1). Multivariate Cox regression analysis revealed that TNC expression was significantly correlated with VM formation $\left(\chi^{2}=13.788, p=\right.$ 0.001 , Table 1) but not with age, tumor size, or sex (Table 2). Kaplan-Meier analysis indicated that GBM patients with increased TNC expression, VM positivity, or both had shorter survival times $(p=0.011, p=0.0009$, and $p=$ 0.0041 , respectively) than those without either or both of these features (Fig. 1f-h). These results indicate that TNC expression levels are correlated with the glioma grade and $\mathrm{VM}$ formation and potentially predict a poor prognosis in glioma patients.

TNC expression was correlated with VM formation in vitro

To clarify the role of TNC in VM formation, we assessed VM formation in glioma cells in vitro. As shown in Fig. 2a, among the five glioma cell lines used herein, U251 and A172 cells formed typical closed circle-like VM structures (the blue mesh indicates VM structures), while U138, U373, and LNZ308 cells exclusively formed open branch-like structures. As expected, TNC was upregulated in U251 and A172 cells but downregulated in U138, U373, and LNZ308 cells (Fig. 2b), in accordance with the VM formation ability $(r=0.938, p<0.05$, Fig. 2c). The VM formation ability was also evaluated in four primary cultured low-passage glioma cells (less than 10 passages) derived from glioma patients. Glioma cells with high TNC expression formed more closed circle-like VM structures and vice versa (Fig. 2d, e). To further confirm the role of TNC in VM formation, TNC $(10 \mu \mathrm{g} / \mathrm{ml})$ was exogenously supplemented in suspensions of U138, U373, and LNZ308 cells, and the cells were subjected to three-dimensional culturing. Eight hours later, the VM formation was significantly greater in TNC-treated than in untreated cells $(p<0.05$; Fig. 2f, g), suggesting that TNC is involved in $\mathrm{VM}$ formation in glioma cell lines.

\section{TNC knockdown attenuated VM formation in vitro and in vivo}

To determine the precise role of TNC in VM formation, we knocked down TNC in U251 and A172 cells with two specific shRNA sequences and control scramble shRNA. TNC was successfully knocked down in U251 and A172 cells $(* * * 0<0.001$, Fig. $3 \mathrm{a}, \mathrm{b})$, and VM was significantly reduced in these cells $\left({ }^{*} p<0.05,{ }^{* * *} p<0.01\right.$; Fig. 3c). Upon treatment of TNC-knockdown cells with exogenous TNC, $\mathrm{VM}$ formation normalized to baseline levels $(" p<0.05$, "* $p<0.01$; Fig. 3d, e). Upon TNC knockdown, glioma growth was significantly inhibited in mice bearing subcutaneous xenograft of U251 cells (***; $p<0.001$, Fig. 3f-h). The orthotopic animal model also shown that those mice injected U251 cell after TNC knockdown survived longer. Histologic analysis of brain specimens from xenografts demonstrated a significant decrease in tumor volume after TNC-knockdown at 25 days post implantation (black arrows indicate tumor location) ${ }^{* * * *} p<0.001$, Fig. $\left.3 \mathrm{k}, \mathrm{l}\right)$. Furthermore, VM (CD31 ${ }^{-} / \mathrm{PAS}^{+}$, Red arrows) in U251 xenograft tissues was significantly decreased in $\operatorname{sh} \# 1$ and sh\#2 groups compared with that in the shNC group $\left({ }^{* * * * *} p<0.001\right.$, Fig. 3i, j; Supplementary Fig. S1C, D). Therefore, our data support the hypothesis that TNC is involved in VM formation in glioma cells. 
A
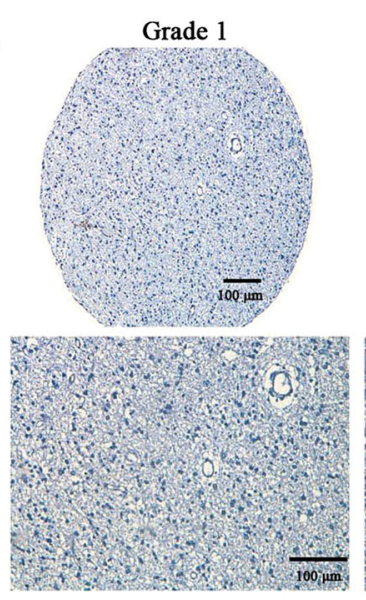

B

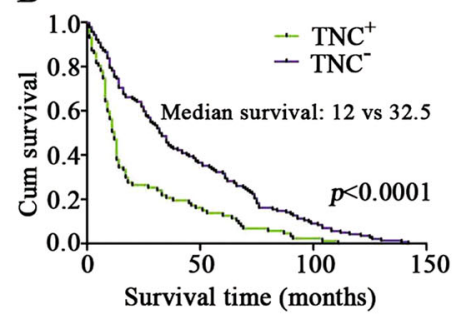

C

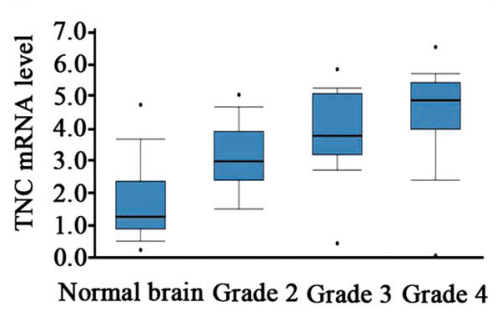

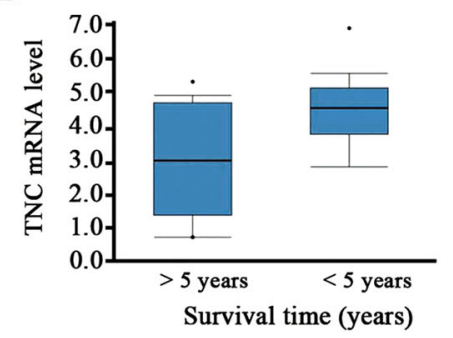

E

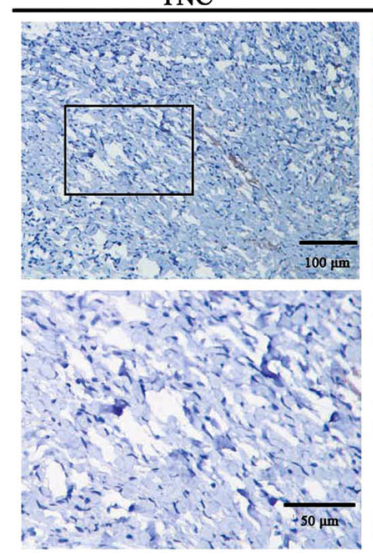

F

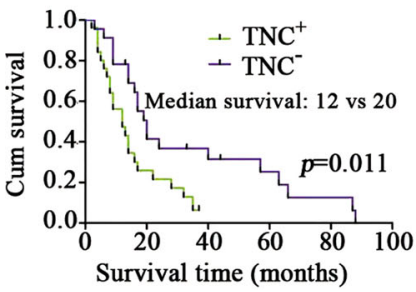

$\mathrm{TNC}^{+}$

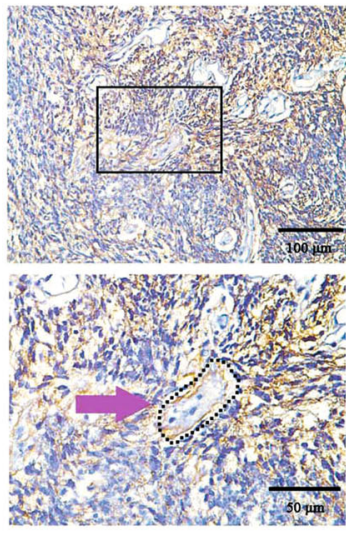

VM Vessel
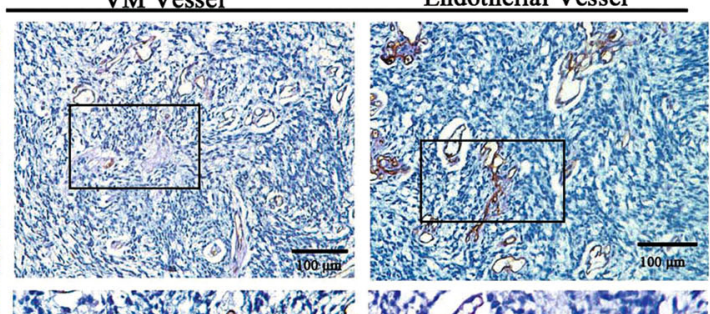

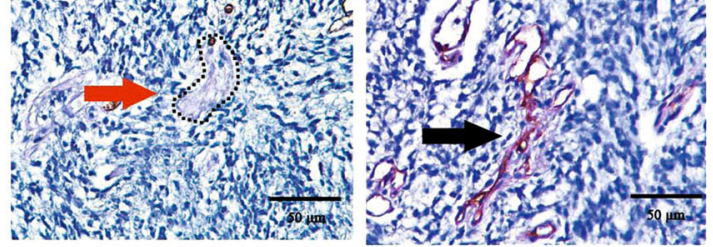

G

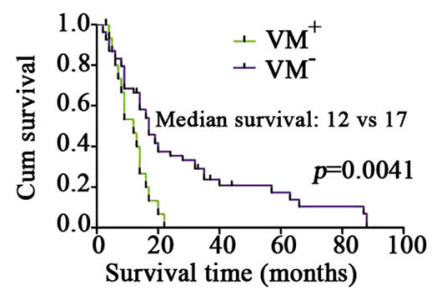

H

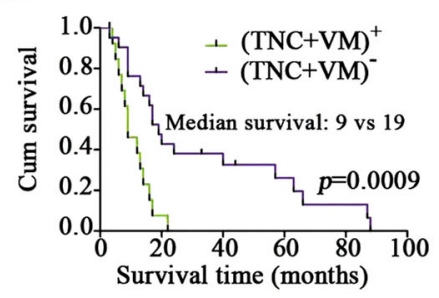

Fig. 1 (See legend on next page.) 
(see figure on previous page)

Fig. 1 Tenascin-c (TNC) was upregulated with an increase in the pathological grade of glioma and vasculogenic mimicry (VM) formation. a Representative images of TNC expression in differently graded gliomas, as examined via immunohistochemistry. Scale bar $=100 \mu \mathrm{m}$.

b Kaplan-Meier survival curve showing that TNC upregulation is correlated with poor prognosis in glioma patients $(p<0.001)$. c , d Analysis of

ONCOMINE datasets show TNC mRNA upregulation in glioma (normal brain and grade II, III and IV; $n=23,45,31$, and 81, respectively; Sun Brain Statistics dataset) and that patients with high TNC expression $(n=13)$ have a lower 5 -year survival rate than those with low TNC expression $(n=413)$ (TCGA Brain Statistics dataset). e IHC results of VM vessels, endothelial cell-lined vessels, and TNC expression in patient-derived glioblastoma samples. The black arrows indicate endothelial cell-lined vessels; the red arrows indicate VM vessels (non-endothelial cell-lined and PAS-positive channels); TNC $^{-}$indicates TNC-negative glioma tissues; TNC $^{+}$indicates TNC-positive glioma tissues. Scale bar $=100 \mu \mathrm{m}$ (upper), Scale bar $=50 \mu \mathrm{m}$ (lower).

$\mathbf{f}-\mathbf{h}$ The Kaplan-Meier survival curves show that TNC upregulation and/or VM-positivity are associated with a poor prognosis $(p<0.05)$.

Table 1 The correlation between vasculogenic mimicry formation with clinicopathological features in $\mathbf{5 0}$ glioblastoma samples.

$\begin{array}{lll}\text { No. } & \text { VM } & \\ & \text { Positive Negative } & \\ & & \\ & \end{array}$

Sex

$\begin{array}{llll}\text { Male } & 33 & 14 & 19 \\ \text { Female } & 17 & 3 & 14 \\ \text { Age (years) } & & & \\ <50 & 27 & 8 & 19 \\ \geq 50 & 23 & 9 & 14\end{array}$

Tumor size (diameter)

$\begin{array}{llll}<5 & 21 & 10 & 11 \\ \geq 5 & 29 & 7 & 22 \\ \text { IDH } & & & \\ \text { Yes } & 7 & 3 & 4 \\ \text { No } & 43 & 14 & 29 \\ \text { MGMT } & & & \\ \text { Yes } & 25 & 10 & 15 \\ \text { No } & 25 & 7 & 18\end{array}$

Preoperative epilepsy

$\begin{array}{llll}\text { Yes } & 10 & 4 & 6 \\ \text { No } & 40 & 13 & 27 \\ \text { MVD } & & & \\ <\text { median } & 28 & 5 & 23 \\ \text { >median } & 22 & 12 & 10\end{array}$

Extent of tumor

resection

\begin{tabular}{lccccc} 
Gross total/subtotal & 38 & 13 & 25 & 0.000 & $1.000^{\mathrm{b}}$ \\
Partial & 12 & 4 & 8 & & \\
TNC & & & & & \\
Positive & 27 & 15 & 12 & 13.788 & $0.001^{\mathrm{a}}$ \\
Negative & 23 & 2 & 21 & & \\
\hline
\end{tabular}

${ }^{\text {aPearson's }} \chi^{2}$ test (asymptotic significance, two-sided)

${ }^{b}$ Continuity correction (two-sided)
Table 2 The correlation between tenascin-c expression with clinicopathological features in $\mathbf{5 0}$ glioblastoma samples.

\begin{tabular}{|c|c|c|c|c|c|}
\hline & \multirow[t]{2}{*}{ No. } & \multicolumn{2}{|l|}{ TNC } & \multirow[t]{2}{*}{$x^{2}$} & \multirow[t]{2}{*}{$p$-value } \\
\hline & & Positive & Negative & & \\
\hline \multicolumn{6}{|l|}{ Sex } \\
\hline Male & 33 & 19 & 14 & 0.500 & $0.48^{a}$ \\
\hline Female & 17 & 8 & 9 & & \\
\hline \multicolumn{6}{|l|}{ Age } \\
\hline$<50$ & 27 & 13 & 14 & 0.809 & $0.368^{a}$ \\
\hline$\geq 50$ & 23 & 14 & 9 & & \\
\hline \multicolumn{6}{|l|}{ Tumor size (diameter) } \\
\hline$<5$ & 21 & 10 & 11 & 0.593 & $0.441^{a}$ \\
\hline$\geq 5$ & 29 & 17 & 12 & & \\
\hline \multicolumn{6}{|l|}{$\mathrm{IDH}$} \\
\hline Yes & 7 & 1 & 6 & 3.476 & $0.062^{b}$ \\
\hline No & 43 & 26 & 17 & & \\
\hline \multicolumn{6}{|l|}{ MGMT } \\
\hline Yes & 25 & 13 & 12 & 0.081 & $0.777^{\mathrm{a}}$ \\
\hline No & 25 & 14 & 11 & & \\
\hline \multicolumn{6}{|l|}{ Preoperative epilepsy } \\
\hline Yes & 10 & 5 & 5 & 0.000 & $1.000^{\mathrm{b}}$ \\
\hline No & 40 & 22 & 18 & & \\
\hline \multicolumn{6}{|l|}{ MVD } \\
\hline$<$ median & 28 & 6 & 22 & 27.179 & $0.001^{a}$ \\
\hline >median & 22 & 21 & 1 & & \\
\hline \multicolumn{6}{|l|}{ Extent of tumor } \\
\hline \multicolumn{6}{|l|}{ resection } \\
\hline Gross total/subtotal & 38 & 21 & 17 & 0.102 & $1.000^{\mathrm{a}}$ \\
\hline Partial & 12 & 6 & 6 & & \\
\hline \multicolumn{6}{|l|}{ VM } \\
\hline Positive & 17 & 15 & 2 & 12.154 & $0.001^{a}$ \\
\hline Negative & 33 & 12 & 21 & & \\
\hline
\end{tabular}

${ }^{\text {aPearson's }} X^{2}$ test (asymptotic significance, two-sided)

${ }^{b}$ Continuity correction (two-sided) 
A
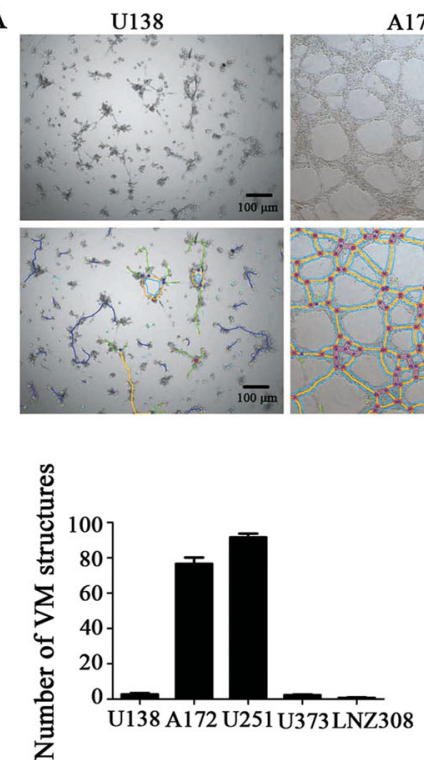

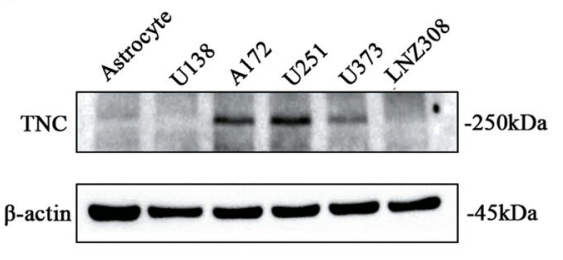

C

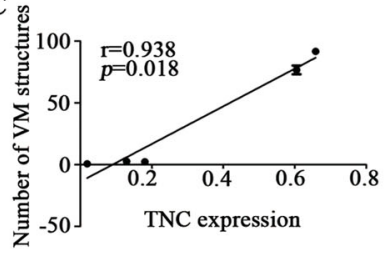

E

\section{$-100$}

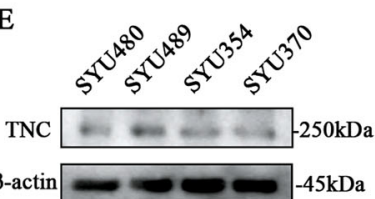

D SYU480
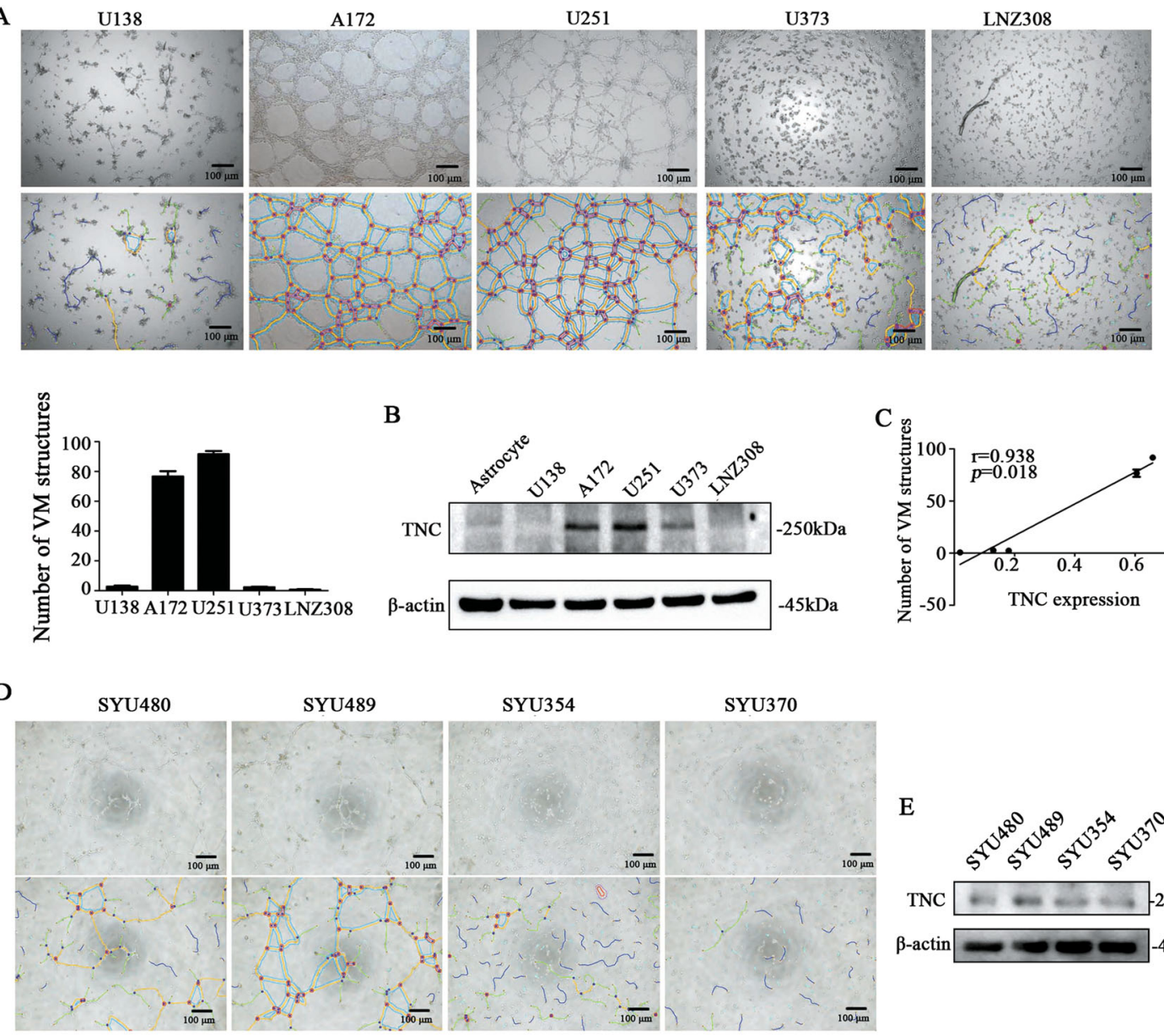

F
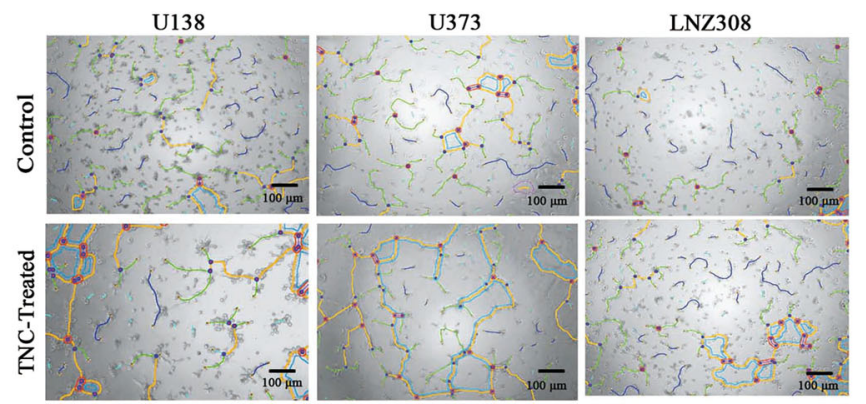

G

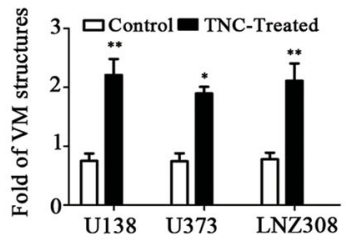

Fig. 2 Tenascin-c (TNC) expression is correlated with vasculogenic mimicry (VM) formation in glioma cells. a Different potentials for VM formation in five glioma cell lines were assessed via 3D Matrigel culturing in vitro, which is a universal method for VM evaluation in vitro. Both U251 and A172 cells formed VM-like structures, while U373, U138, and LNZ308 cells did not (the blue mesh indicates VM-like structures). Scale bar $=$ $100 \mu \mathrm{m}$. b Western blot analysis revealed that TNC was upregulated in U251 and A172 cells rather than in U373, U138 and LNZ308 glioma cell lines ( $\beta$-actin used as the loading control). c Correlation analysis revealed that the number of VM structures was correlated with TNC protein expression $(r=0.938, p<0.05)$. d, e VM formation ability was stronger in primary cultured cells with higher level of TNC than those with low level of TNC. Glioma cell SYU489 formed VM-like structures, while SYU480, SYU354, and SYU370 did not. At the meanwhile, the expression level of TNC was higher in SYU489 rather than in SYU480, SYU354, and SYU370. f, g Exogenous TNC $(10 \mu \mathrm{g} / \mathrm{ml})$ was used to stimulate U138, U373, and LNZ308 cells for $8 \mathrm{~h}$, and the number of VM structures increased in comparison with that in the control groups. Scale bar $=100 \mu \mathrm{m} .\left(^{*} p<0.05,{ }^{* *} p<0.01,{ }^{* * *} p<0.001\right)$.

TNC knockdown inhibited proliferation, invasion, migration, and induced apoptotic cell death in glioma cells

VM formation is closely associated with tumor cell proliferation, invasion, and migration ${ }^{24}$. Thus, we investigated the detailed role of TNC in glioma cells. From the 4th passage proliferation was significantly lower in TNC-knockdown U251 and A172 cells than in control cells $\left({ }^{* * * *} p<0.001\right.$, Fig. $\left.4 \mathrm{a}, \mathrm{b}\right)$. Furthermore, TNC 


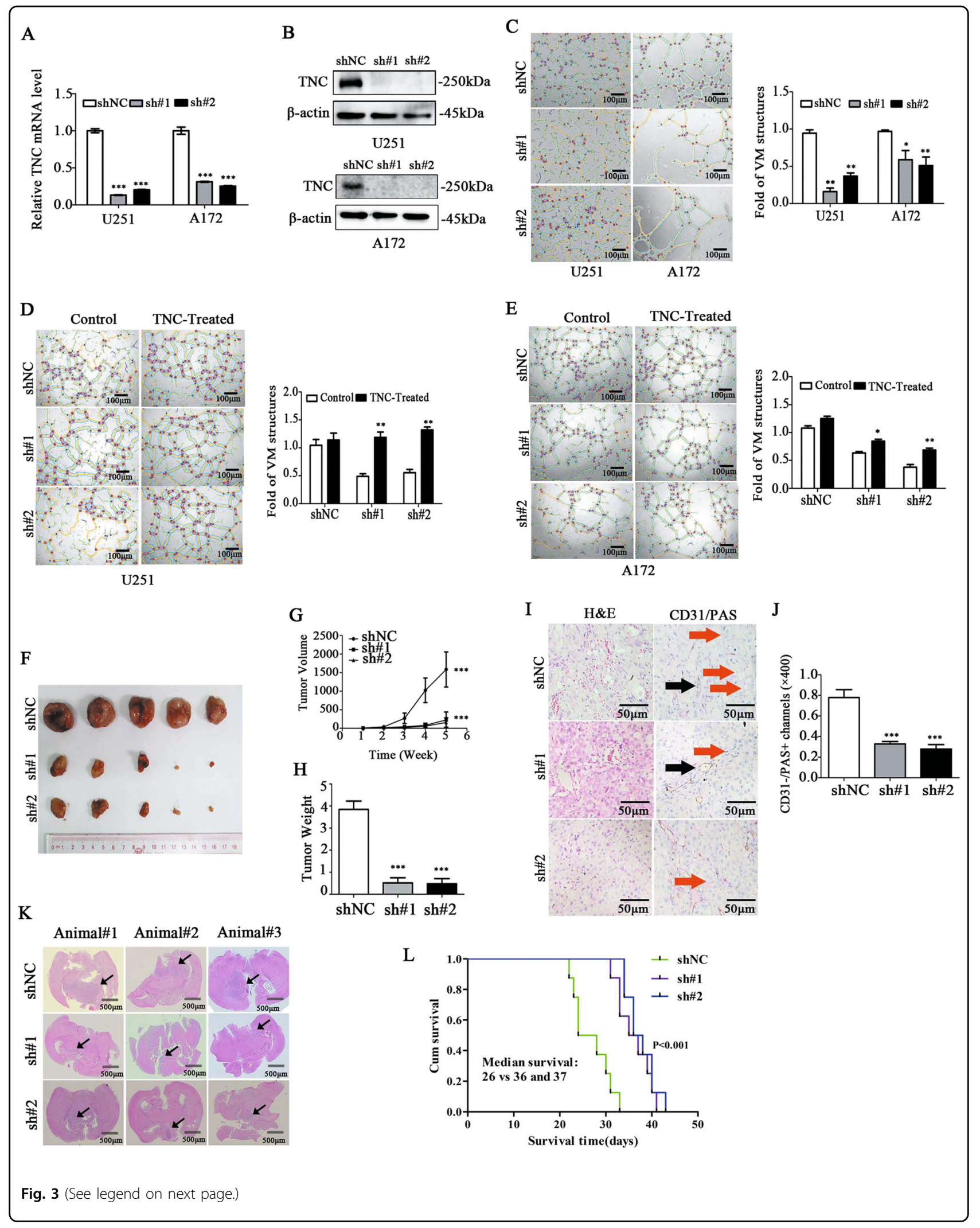


(see figure on previous page)

Fig. 3 Tenascin-c (TNC) knockdown attenuated vasculogenic mimicry (VM) formation in vitro and in vivo. a Total RNA was isolated from the shNC, sh\#1, and sh\#2 groups of U251 and A172 cells and analyzed via RT-qPCR. TNC mRNA was significantly downregulated ( $p<0.01$; GAPDH used as the control). $\mathbf{b}$ Western blot analysis revealed that TNC was significantly downregulated ( $\beta$-actin used as the loading control). $\mathbf{c}$ The number of VM structures in both the sh\#1 and sh\#2 groups of U251 and A172 glioma cells was decreased in comparison with that in the shNC group. Scale bar = $100 \mu \mathrm{m}$. d, e Exogenous TNC exposure for $8 \mathrm{~h}$ increased the number of VM structures in both the sh\#1 and sh\#2 groups of U251 and A172 glioma cells. Scale bar $=100 \mu \mathrm{m} . \mathbf{f}, \mathbf{g}$ TNC knockdown inhibited tumorigenicity in U251 glioma cells. $\mathbf{h}$ Quantification of tumor mass in the shNC, sh\#1, and sh\#2 groups. i Representative images of hematoxylin-eosin staining and CD31/periodic acid-Schiff (PAS) staining (the red arrows indicate typical VM channels; the black arrows indicate classical endothelial cell vessels). $\mathbf{j}$ Quantification of VM channels via CD31/PAS staining in the shNC, sh\#1, and sh\#2 groups (magnification: $\times 400$; scale bar $=50 \mu \mathrm{m}$ ). $\mathbf{k}$ HE staining of brain sections demonstrated a significant decrease in tumor volume after TNCknockdown at 25 days post implantation (black arrows indicate tumor location). I Kaplan-Meier survival curves showing a significant increase in median survival of TNC-knockdown tumor-bearing mice. Scale bar $=500 \mu \mathrm{m}\left({ }^{*} p<0.05,{ }^{* *} p<0.01,{ }^{* * *} p<0.001\right)$.

knockdown induced G2/M arrest in both $\mathrm{U} 251$ and A172 cells (Fig. 4i, j). Transwell and wound-healing assays to investigate the effect of TNC on cell invasion and migration revealed that a significant reduction in both cell invasion and migration upon TNC knockdown $\left({ }^{*} p<0.05\right.$, ${ }^{* *} p<0.01$; Fig. 4c, d, Supplementary Fig. S1A, B). Furthermore, the rate of wound healing was significantly decreased in TNC-knockdown cells $\left({ }^{*} p<0.05\right.$, Fig. $\left.4 \mathrm{e}-\mathrm{h}\right)$. Given that stromal-derived TNC increases metastasis by reducing apoptosis and inducing the cellular plasticity of cancer cells ${ }^{25}$, we then investigated whether TNCknockdown induced apoptosis in glioma cell. As expected, TNC-knockdown increased Annexin V positive cells in both U251 and A172 glioma cells ( ${ }^{*} p<0.05,{ }^{* * *} p<0.01$; Fig. 4k, l). These results indicated that TNC is involved in cell proliferation, cell cycle progression, invasion, and migration in glioma cells.

\section{TNC knockdown inhibited Akt phosphorylation and downregulated MMP2/9}

VM formation involves numerous factors including VEcadherin, Twist, VEGFR2, Akt, and MMP2/ $/ 9^{26-28}$. Herein, $M M P 2$ and $M M P 9$ mRNA (primer sequence described in Supplementary Table 2) were significantly downregulated in TNC-knockdown cells (Fig. 5a, b). Since MMP2 and MMP9 are important downstream effectors of Akt, herein, TNC knockdown impaired Akt phosphorylation at both $\mathrm{Ser}^{473}$ and $\mathrm{Thr}^{308}$ and downregulated MMP2 and MMP9 (Fig. 5c). Gelatin zymography confirmed that MMP2 and MMP9 activity were reduced in culture supernatants in TNC-knockdown cells (Fig. 5d). IHC analysis of U251 subcutaneous and intracranial xenografts tissues revealed that Akt phosphorylation at $\mathrm{Ser}^{473}$ and MMP2 and MMP9 expression were decreased (Fig. 5e and Supplementary Fig. S1E). These data show that TNC knockdown decreases Akt phosphorylation and MMP2/9 activity.

\section{MK-2206 treatment downregulated MMP2 and MMP9 and inhibited VM formation}

To determine that Akt phosphorylation mediates MMP2/MMP9 expression and VM formation, MK-2206, a highly selective small molecular inhibitor blocks the phosphorylation of Akt1, Akt2, and Akt3, was used. As expected, VM was reduced gradually in a dose-dependent manner in U251 and A172 cells upon exposure to MK2206 at $0,5,10$, and $20 \mu \mathrm{M}$ for $24 \mathrm{~h}$ (Fig. 6a). Furthermore, Akt phosphorylation at $\mathrm{Ser}^{473}$ and $\mathrm{Thr}^{308}$ residues and MMP2 and MMP9 were downregulated in cells treated with MK-2206 at 2, 4, and $8 \mu \mathrm{M}$ for $24 \mathrm{~h}$ (Fig. 6b). Gelatin zymography after MK-2206 treatment indicated are duction in MMP2 and MMP9 activity (Fig. 6c). A rescue assay revealed that both Akt phosphorylation at $\mathrm{Ser}^{473}$ and $\mathrm{Thr}^{308}$ residues and MMP2 and MMP9 expression levels in the sh\#2 group were increased upon treatment with exogenous TNC and decreased upon treatment with MK2206 at $10 \mu \mathrm{M}$ for $24 \mathrm{~h}$ (Fig. 6d). As expected, the VM formation assay revealed consistent results with the rescue assay (Fig. 6e, f). These data show that MK-2206 treatment decreased Akt phosphorylation and MMP2/9 activity, further reducing VM formation, indicating that the Akt/MMP2/MMP9 axis is involved in TNC-regulated $\mathrm{VM}$ formation.

\section{Discussion}

High-grade glioma is characterized by a highly vascularized tumor. Anti-angiogenesis therapy might be a new method for high-grade glioma patients since Folkman et al. proposed the tumor angiogenesis theory in $1971^{1}$. Common genetic alterations in GBM like amplification of the epidermal growth factor receptor (EGFR) and its mutant EGFRVIII promote angiogenesis in GBM implying an important role of endothelial vessels in GBM development ${ }^{29}$. However, tumor cell-derived patterns, such as $\mathrm{VM}^{30}$, potentially play a vital role in tumorigenesis and contribute to anti-angiogenesis therapeutic resistance. Bevacizumab abrogates endothelial cell-driven angiogenesis but not VM formation ${ }^{31}$. The mechanism underlying VM formation is unclear, although it was proposed by Maniotis et al. in $1999^{7}$. Our finding that TNC promotes VM formation by glioma cells further indicates an important role of TNC in glioma pathogenesis. 


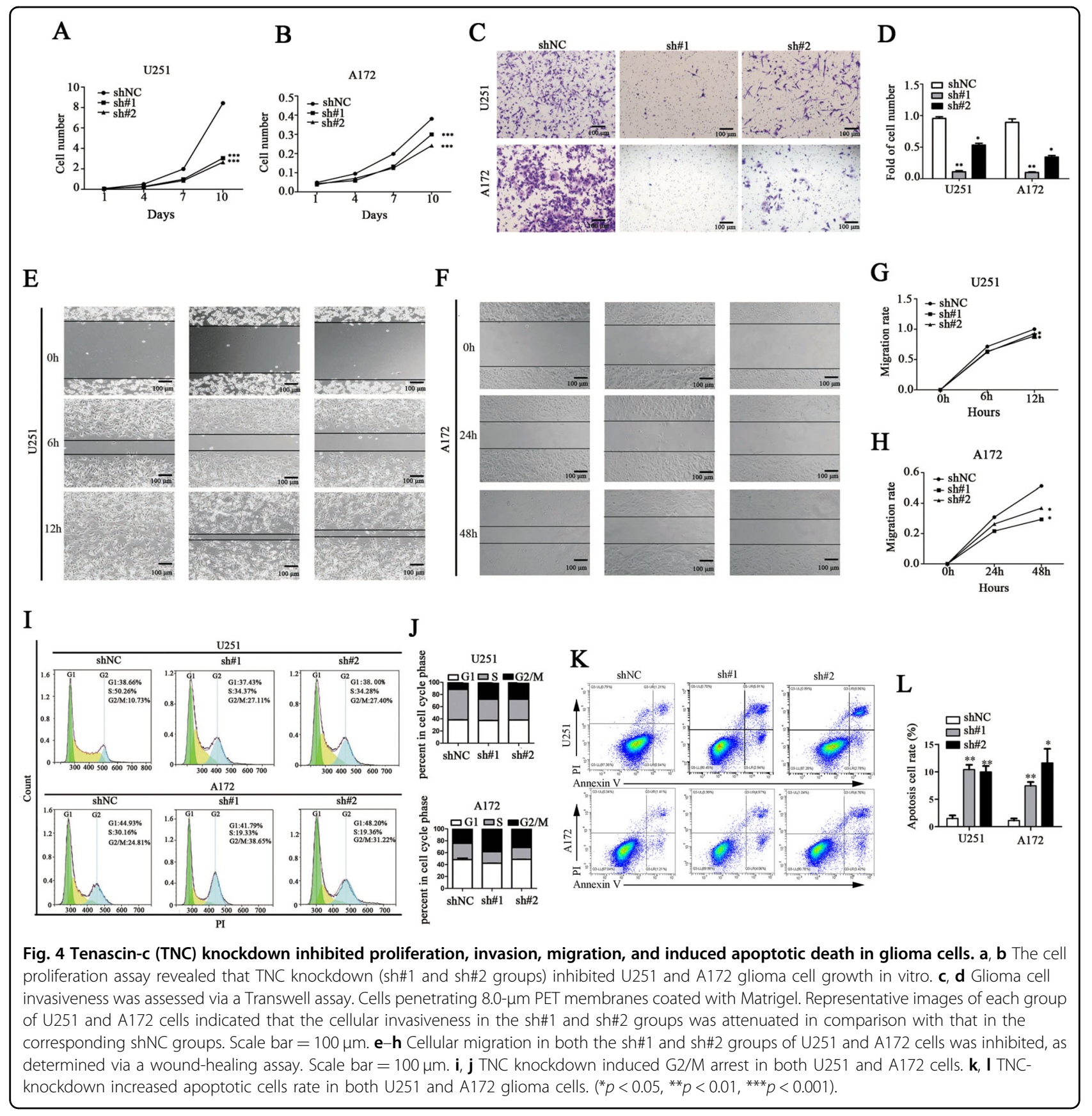

The present results confirmed TNC upregulation in glioma tissues, especially in GBM tissues and show that $34 \%$ of samples were VM-positive, as reported previously $^{32}$. We assessed VM formation in glioma cell lines and low-passaged primary cultured glioma cells, and found that TNC expression levels correlated with VM formation ability. Exogenous TNC promoted VM formation by glioma cells, thus indicating a direct interaction between TNC and VM formation. Furthermore, TNC knockdown decreased VM formation in vitro and in vivo. Tumor cell proliferation, invasiveness, and migration are critical for VM formation; ${ }^{33}$ concurrently, cell growth, invasion, and migration were inhibited upon TNC knockdown. Furthermore, TNC knockdown significantly induced G2/M arrest and apoptotic cell death in glioma cells. Assessment of VM markers in U251 and A172 cells after TNC knockdown revealed that MMP2 and MMP9 mRNA were significantly downregulated. MMP2 and MMP9 are important downstream effectors of Akt and contribute to VM formation ${ }^{24}$. We investigated whether TNC impaired VM formation in glioma cells upon a reduction in Akt phosphorylation and MMP2/9 
A

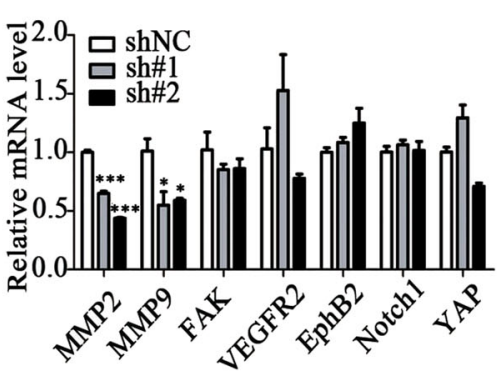

$\mathrm{B}$

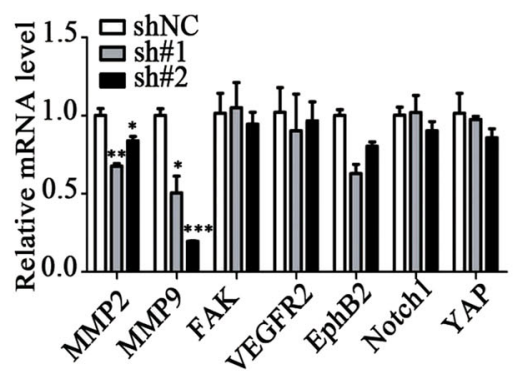

$\mathrm{C}$

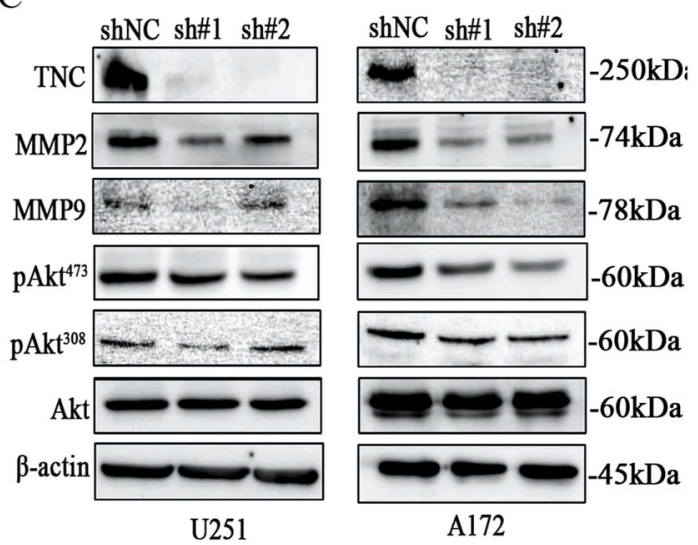

D

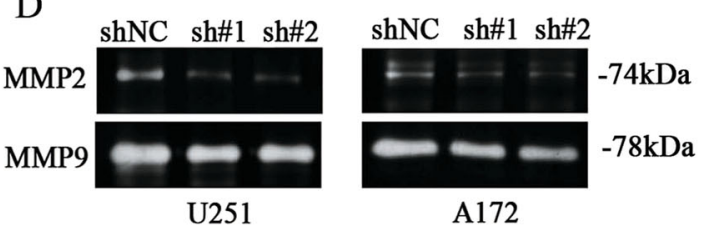

$\mathrm{E}$

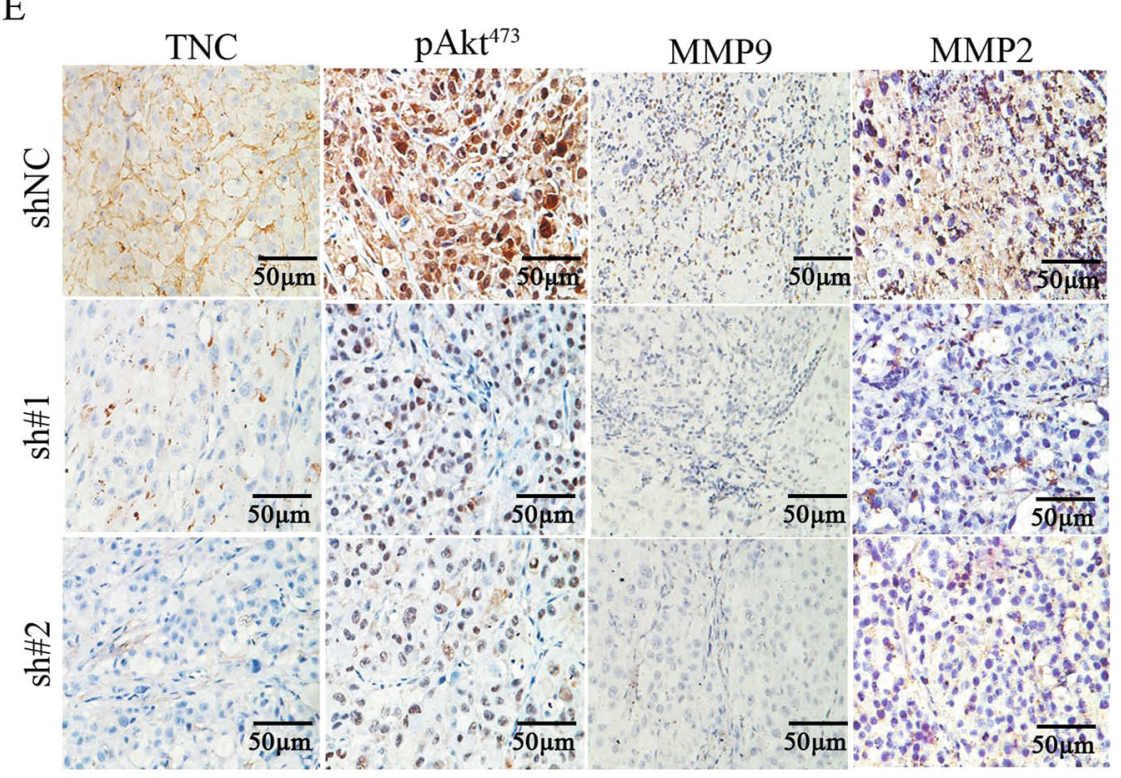

Fig. 5 Tenascin-c (TNC) knockdown inhibited Akt phosphorylation and downregulated matrix metalloproteinase (MMP) 2/9. a, b Total RNA was isolated from the shNC, sh\#1, and sh\#2 groups of U251 and A172 cells. The mRNA levels of VM-related markers were analyzed via RT-qPCR (GAPDH used as the internal control). MMP2 and MMP9 mRNA were significantly downregulated. c Akt phosphorylation at Ser ${ }^{473}$ and Thr ${ }^{308}$ residues and MMP2 and MMP9 expression were decreased after TNC knockdown ( $\beta$-actin used as the control). $\mathbf{d}$ MMP2/9 activity was inhibited, as confirmed via zymography. e TNC, pAKT, MMP2, and MMP9 downregulation in tumor tissues from xenografts with TNC knockdown (magnification: $\times 400 ;$ scale bar $=50 \mu \mathrm{m}) .\left({ }^{*} p<0.05,{ }^{* *} p<0.01,{ }^{* * *} p<0.001\right)$.

downregulation. Indeed, TNC knockdown decreased Akt phosphorylation at $\mathrm{Ser}^{473}$ and $\mathrm{Thr}^{308}$ residues and downregulated MMP2/9. Furthermore, MK-2206 was used to inhibit Akt phosphorylation at both $\mathrm{Ser}^{473}$ and $\mathrm{Thr}^{308}$ residues; consequently, VM decreased in a dosedependent manner. We demonstrated that TNC promoted VM formation by activating Akt phosphorylation and inducing MMP2/MMP9 expression. Left panel, Extracellular protein TNC activates Akt phosphorylation and then stimulates the expression of MMP2/MMP9, which further promotes VM formation. Right panel, TNC-knockdown decreases Akt phosphorylation and 


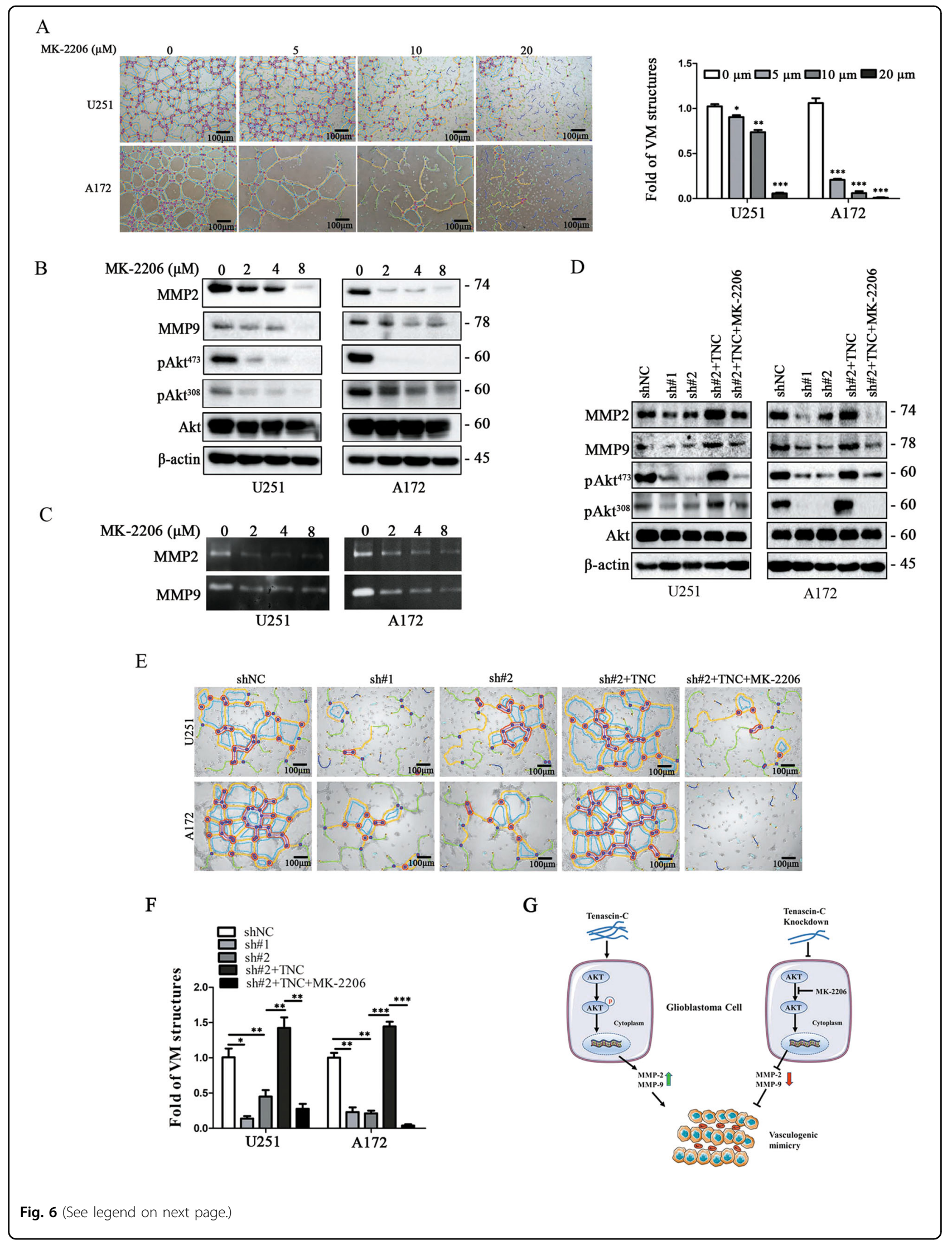


(see figure on previous page)

Fig. 6 MK-2206 treatment downregulated matrix metalloproteinase (MMP) 2/9 and inhibited vasculogenic mimicry (VM) formation. a VM formation was assessed in U251 and A172 cells after exposure to the Akt phosphorylation inhibitor MK-2206 at 0, 5, 10, and $20 \mu \mathrm{M}$ for $24 \mathrm{~h}$. The number of VM structures decreased in a dose-dependent manner. (magnification: $\times 100$; scale bar $=100 \mu \mathrm{m}$ ). $\mathbf{b}$ Immunoblotting revealed that MMP2/ 9 expression and Akt phosphorylation at both $\mathrm{Ser}^{473}$ and $\mathrm{Thr}^{308}$ residues were significantly downregulated in a dose-dependent manner after MK2206 treatment. c Zymography revealed that MMP2 and MMP9 activity was inhibited after MK-2206 treatment. d Immunoblotting revealed that MMP2/9 expression and Akt phosphorylation at both $\mathrm{Ser}^{473}$ and $\mathrm{Thr}^{308}$ residues were increased after TNC treatment for $24 \mathrm{~h}$ and decreased upon combinatorial treatment with TNC and $10 \mu \mathrm{M}$ MK-2206. e, f The VM formation assay revealed that VM structures increased after TNC treatment for $24 \mathrm{~h}$ and decreased upon combinatorial treatment with TNC and $10 \mu \mathrm{M}$ MK-2206. $\mathbf{g}$ A model describing the mechanism of how TNC involved the regulation of VM formation process. $\left({ }^{*} p<0.05,{ }^{* *} p<0.01\right.$, $\left.{ }^{* * *} p<0.001\right)$.

MMP2/MMP9 expression, as well as downstream VM formation. Similarly, small molecular inhibitor MK-2206 attenuates Akt phosphorylation, which decreases expression of MMP2/MMP9 and VM formation (Fig. 6g). These results suggest that Akt phosphorylation and MMP2/9 expression play an important role in TNC-induced VM formation.

In conclusion, our results show that TNC promotes VM formation in glioma, thus potentially contributing to anti-angiogenic therapeutic resistance. Our results show that an Akt/MMP2/MMP9 axis potentially regulates VM formation in glioma. Therefore, targeting TNC expression is a potentially useful method to inhibit $\mathrm{VM}$ formation in glioma and decrease anti-angiogenic therapeutic resistance.

\section{Materials and methods \\ Patients and cell lines}

Fifty glioblastoma (GBM) specimens and a tissue array (229 glioma samples) were obtained from patients who received surgery at Sun Yat-sen University Cancer Center (SYSUCC) between 2001 and 2016 with written informed consent. General information of the cohorts is summarized in Tables 1, 2 and Supplementary Table 1. Tumors were pathologically diagnosed by experienced pathologists. Overall survival (OS) of the patients was defined as the period from the day of surgery to death. The latest follow-up data were updated on December 31, 2017. Experiments were conducted in accordance with the guidelines and approved by the Ethics Committee of SYSUCC.

Cell line U251 and U373 were maintained from the State Key Laboratory of Oncology in South China. A172, U138, LNZ308 and normal astrocyte cell line (Ast) were obtained from Dr. Shing-shun Tony To, Department of Health Technology and Informatics, The Hong Kong Polytechnic University. All these cell lines were authenticated by STR profiling within 6 months. Astrocytes were cultured in astrocyte medium (ScienCell Research Laboratories, Carlsbad, CA,) supplemented with fetal bovine serum, astrocyte growth supplement, and penicillin/streptomycin. Purified human Tenascin-c protein was purchased from EMD/Millipore (Darmstadt, Germany).

\section{Tumor specimens and primary cell culture}

Four primary high-grade glioma specimens were obtained freshly from the operating room following protocols approved by the research ethics committee in the Sun Yat-Sen University Cancer Center with informed consent obtained from all subjects. Primary glioma cell lines named (SYU480, anaplastic astrocytoma; SYU489, glioblastoma; SYU354, glioblastoma; SYU370, anaplastic astrocytoma) were isolated and subsequently cultured in DMEM supplemented with $10 \%$ fetal bovine serum and penicillin/streptomycin as reported by Jun Fu et $\mathrm{al}^{34}$.

\section{Immunohistochemical (IHC) staining}

IHC staining was performed as reported previously ${ }^{35}$. The expression level of TNC in glioma tissues was scored as the proportion of the area with positive staining $(0-100 \%)$ multiplied by the staining intensity $(0$, negative; 1 , weak; 2 , moderate; 3 , intense). The scores were determined by two pathologists independently. The median score was chosen as the cut-off value for defining high and low expression. Sections were probed with primary antiTNC (ab108930, Abcam, Cambridge, MA), anti-CD31 (ab134168, Abcam), anti-pAkt (4060P, Cell Signaling Technologies [CST], Danvers, MA,), anti-matrix metalloproteinase (MMP) 2 (ab86607, CST), and anti-MMP9 (ab76003, Abcam) antibodies overnight at $4{ }^{\circ} \mathrm{C}$, and the antibodies were detected using the DAB system (Golden Bridge, Beijing, China).

\section{TNC knockdown}

TNC was silenced in U251 and A172 glioma cells, using shRNA vectors based on the pLKO.1 plasmid (\#10879, Addgene, Watertown, MA). Two sequences targeting human TNC, along with a negative control sequence, were used. Lipofectamine 3000 (Invitrogen, Carlsbad, CA) was used for transfection in accordance with the manufacturer's protocol. Transfected cells were cultured in selection media supplemented with $2 \mu \mathrm{g} / \mathrm{ml}$ puromycin (MCE, Monmouth Junction, NJ) for 2 weeks. 


\section{Proliferation assay}

The role of TNC in glioma cell proliferation was evaluated via cell growth assays, as reported previously ${ }^{35}$. Briefly, 5000 cells were seeded in each well in 6-well plates. The cell number was determined using a Celigo system every $3 \mathrm{~d}$ (Nexcelom Bioscience LLC, Lawrence, MA). Each cell line was plated in triplicate, and the experiments were repeated at least three times.

\section{Cell cycle analysis}

Cells were harvested, fixed with $70 \%$ ethanol overnight at $4{ }^{\circ} \mathrm{C}$, and stained with propidium iodide (KeyGEN, Jiangsu, China) in the dark for $1 \mathrm{~h}$. Cell suspensions were subjected to flow cytometry with an ACEA NovoCyte system (ACEA Biosciences, Inc., Santa Clara, CA). Cell cycle distribution was analyzed with 100,000 events for each sample.

\section{Flow cytometry analysis}

Flow cytometry analysis was used to detected apoptotic cell death. Briefly, cell suspensions were blocked with $10 \%$ BSA for $10 \mathrm{~min}$. Apoptosis were detected using Annexin V-FITC/PI detection kit (BD biosciences, New Jersey, USA). Flow cytometry analysis was performed using a CytoFLEX (Beckman Coulter Inc., CA, USA) flow cytometer equipped with CytExpert software with 20,000 events recorded for each sample.

\section{Cell invasion and migration assays}

Serum-free cell suspensions containing $5 \times 10^{4}$ cells were seeded in the upper chamber coated with or without Matrigel for invasion or migration assays, respectively. DMEM medium supplemented with $10 \%$ fetal bovine serum was added to the bottom chamber. After incubation at $37^{\circ} \mathrm{C}$ for $24 \mathrm{~h}$, the migrated cells were fixed in $10 \%$ formalin and stained with $0.4 \%$ crystal violet. Images were captured in five random fields, and cells were enumerated using a bright-field microscope $(100 \times)$. Each experiment was performed independently in triplicate.

\section{Wound healing assay}

Cells were cultured in 6-well plates up to $80-90 \%$ confluence. An even scratch was made in the middle of each well, using a $10-\mu$ l pipette tip, and cells were then washed with PBS and incubated in serum-free medium at $37^{\circ} \mathrm{C}$ for $48 \mathrm{~h}$. Images of the wounds were captured every $6 \mathrm{~h}$, and the wound closure ratio was determined as the ratio of the distance of cell migration to the width of the wound at $0 \mathrm{~h}$ until the wounds were closed.

\section{Quantitative real-time PCR analysis}

Total RNA was extracted with TRIzol (Invitrogen) and reverse-transcribed to cDNA using a cDNA Synthesis kit
(Invitrogen) in accordance with the manufacturer's protocol. Real-time quantitative PCR (qRT-PCR) was subsequently performed using a Bio-Rad CFX96 Real-Time PCR System (Bio-Rad Laboratories, Inc., Hercules, CA). All samples were analyzed in triplicate, and mRNA expression was normalized to that of the housekeeping gene $G A P D H$, using the $2^{-\triangle \Delta C t}$ method.

\section{Three-dimensional culturing}

VM formation ability in vitro was assessed via threedimensional culturing. Briefly, 96-well plates were coated with $50 \mu \mathrm{l}$ of Matrigel (BD Biosciences, Sparks, MD), and cell suspensions were seeded on Matrigel and incubated for $8 \mathrm{~h}$ at $37^{\circ} \mathrm{C}$. Five random fields per well were imaged using a bright-field microscope (magnification, $\times 100$ ). The experiment was performed in triplicate. The total number of cells on the mesh was determined and analyzed using ImageJ software (National Institutes of Health, Bethesda, MD).

\section{Western blot analysis}

Western blot analysis was performed using a standard protocol $^{36}$. Briefly, equal amounts of protein $(30 \mu \mathrm{g})$ were separated via SDS-PAGE and electro-transferred onto polyvinylidene difluoride membranes (EMD Millipore). Membranes were probed with primary anti-TNC (ab108930, Abcam), anti-MMP2 (ab86607, Abcam), anti-MMP9 (ab76003, Abcam), anti-pan-Akt (4691 s, CST), anti-pAkt ${ }^{473}$ (4060 P, CST), anti-pAkt ${ }^{308}$ (sc135650, Santa Cruz Biotechnology, Santa Cruz, CA), anti$\beta$-actin $(8457 \mathrm{~S}, \mathrm{CST})$ antibodies and then probed sequentially with secondary goat anti-mouse and antirabbit antibodies (7076P2, 7074P2, CST) and visualized using an enhanced chemiluminescence kit (Beyotime, Shanghai, China).

\section{Gelatin zymography}

Total proteins were extracted from culture supernatants and separated via PAGE on $7.5 \%$ polyacrylamide gels containing $0.5 \%$ gelatin (Macklin, Shanghai, China). Gels were then equilibrated with $2.5 \%$ Triton $\mathrm{X}-100$ and incubated in substrate buffer $(50 \mathrm{mmol} / \mathrm{L}$ Tris- $\mathrm{HCl}[\mathrm{pH}$ 7.5], $150 \mathrm{mmol} / \mathrm{L} \mathrm{NaCl}$, and $10 \mathrm{mmol} / \mathrm{L} \mathrm{CaCl}_{2}$ ) for $24 \mathrm{~h}$ at $37^{\circ} \mathrm{C}$. Gels were stained with Coomassie Brilliant Blue G250 (BioFROXX, Guangzhou, China) for $2 \mathrm{~h}$ and washed until clear zones associated with MMP activity were observed.

\section{Akt inhibition via MK-2206 treatment}

Cells were treated with the small-molecule Akt inhibitor MK-2206 (Selleckchem, Houston, TX) for $24 \mathrm{~h}$ at 5, 10, and $20 \mu \mathrm{M}$ for the VM formation assay and 2, 4, and $8 \mu \mathrm{M}$ for Western blot analysis. Cells and culture supernatants were then harvested for subsequent analyses. 


\section{Xenograft animal model}

Mice were allocated to experimental groups randomized before the implantation of tumor cells. For the subcutaneous animal model, U251 cells at a density of $10^{7}$ cells were injected subcutaneously into the flanks of 4-6week-old female BALB/c nude mice $(n=15)$ (Model Animal Research Center of Nanjing University, Nanjing, China). Tumor volumes were monitored every $3 \mathrm{~d}$, and tumor sizes were calculated using the following formula: tumor volume $=0.5 \times$ length $\times(\text { width })^{2}$. Five weeks later, the mice were euthanized, and tumors were dissected out for further IHC analysis.

For the orthotopic animal model, U251 cells resuspended in PBS were intracranially injected $1 \mathrm{~mm}$ lateral and $2 \mathrm{~mm}$ posterior to bregma and $4 \mathrm{~mm}$ deep to the surface of the skull using a micro-syringe and $27 \mathrm{G}$ needle as in our previous study ${ }^{34}\left[n=13 /\right.$ group, $2.0 \times 10^{5}$ cells/ mouse]. Mice $(n=8)$ were observed every 2 day until moribund and then sacrificed. Another cohort $(n=5)$ was sacrificed 25 days post implantation. Brains were removed, embedded in paraffin, and sectioned for $\mathrm{HE}$ staining. All animal experiments were performed in accordance with institutional guidelines and approved by the Animal Care and Use Ethical Committee of SYSUCC.

\section{Statistical analyses}

Data were analyzed using the SPSS software (Version 17.0, Chicago, IL, USA) and are presented as the mean \pm standard deviation (S.D.) or standard error (S.E.M.). Statistical significance was determined at a $p$-value of $<0.05$. Pearson's correlation analysis was performed to determine the correlation between VM and TNC expression. Differences were compared using Student's $t$-test for two groups and one-way ANOVA for multiple groups. Survival probabilities were plotted using the Kaplan-Meier method.

\section{Acknowledgements}

The authors thank Qian Wang and Guo-kai Feng for their technical support. This study was supported by the National Basic Research Program (973, 2015CB755505), the National Natural Science Foundation of China (NSFC) (81372685 and 81872059), the National High Technology Research and Development Program of China $(863,2012$ AA02A508) and Guangzhou Science Technology and Innovation Project (201508020125), and the Science and Technology Planning Project (2016A020213004) and the Natural Science Foundation of Guangdong Province (NSFG) (S2013040012894) to Zhong-ping Chen, the NSFC (81101521, 81572479 and 81772677) and NSFG (2016A030313309) to Jing Wang, the Guangzhou Science Technology and Innovation Project (201803010056) to Yin-sheng Chen, the NSFC (81672484) to Chao Ke.

\section{Conflict of interest}

The authors declare that they have no conflict of interest.

\section{Publisher's note}

Springer Nature remains neutral with regard to jurisdictional claims in published maps and institutional affiliations.
Supplementary information accompanies this paper at (https://doi.org/ 10.1038/s41419-019-2102-3).

Received: 17 June 2019 Revised: 15 October 2019 Accepted: 29 October 2019

Published online: 21 November 2019

\section{References}

1. Folkman, J. Tumor angiogenesis: therapeutic implications. New Engl. J. Med. 285, 1182-1186 (1971).

2. Nghiemphu, P. L. et al. Phase I study of sorafenib and tipifarnib for recurrent glioblastoma: NABTC 05-02. J. Neuro-Oncol. 136, 79-86 (2018).

3. Gilbert, M. R. et al. A randomized trial of bevacizumab for newly diagnosed glioblastoma. New Engl. J. Med. 370, 699-708 (2014).

4. Hu, Y. L., Jahangiri, A., De Lay, M. \& Aghi, M. K. Hypoxia-induced tumor cell autophagy mediates resistance to anti-angiogenic therapy. Autophagy $\mathbf{8}$, 979-981 (2012).

5. Angara, K., Borin, T. F. \& Arbab, A. S. Vascular mimicry: a novel neovascularization mechanism driving anti-angiogenic therapy (AAT) resistance in glioblastoma. Transl. Oncol. 10, 650-660 (2017).

6. Sun, $H$. et al. Anti-angiogenic treatment promotes triple-negative breast cancer invasion via vasculogenic mimicry. Cancer Biol. Ther. 18, 205-213 (2017).

7. Maniotis, A. J. et al. Vascular channel formation by human melanoma cells in vivo and in vitro: vasculogenic mimicry. Am. J. Pathol. 155, 739-752 (1999).

8. Liu, S. et al. S1PR1 regulates the switch of two angiogenic modes by VEcadherin phosphorylation in breast cancer. Cell death Dis. 10, 200 (2019).

9. Zhang, Q. et al. Thymidine phosphorylase promotes malignant progression in hepatocellular carcinoma through pentose Warburg effect. Cell Death Dis. 10, 43 (2019).

10. Wang, W. et al. Epithelial-mesenchymal transition regulated by EphA2 contributes to vasculogenic mimicry formation of head and neck squamous cell carcinoma. BioMed. Res. Int. 2014, 803914 (2014).

11. Zhang, $C$. et al. Galunisertib inhibits glioma vasculogenic mimicry formation induced by astrocytes. Sci. Rep. 6, 23056 (2016).

12. Trisciuoglio, D. et al. BCL-XL overexpression promotes tumor progressionassociated properties. Cell Death Dis. 8, 3216 (2017).

13. Yue, W. Y. \& Chen, Z. P. Does vasculogenic mimicry exist in astrocytoma? J. Histochem. Cytochem. 53, 997-1002 (2005).

14. Wang, S. S. et al. CD133+ cancer stem-like cells promote migration and invasion of salivary adenoid cystic carcinoma by inducing vasculogenic mimicry formation. Oncotarget 7, 29051-29062 (2016).

15. Yang, J. P. et al. Tumor vasculogenic mimicry predicts poor prognosis in cancer patients: a meta-analysis. Angiogenesis 19, 191-200 (2016).

16. Sun, T. et al. Blockade of a laminin-411-Notch Axis with CRISPR/Cas9 or a nanobioconjugate inhibits glioblastoma growth through tumormicroenvironment cross-talk. Cancer Res. 79, 1239-1251 (2019).

17. Roth, P. et al. Integrin control of the transforming growth factor-beta pathway in glioblastoma. Brain 136, 564-576 (2013).

18. Midwood, K. S., Hussenet, T., Langlois, B. \& Orend, G. Advances in tenascin-C biology. Cell. Mol. life Sci. 68, 3175-3199 (2011).

19. Wiese, S., Karus, M. \& Faissner, A. Astrocytes as a source for extracellular matrix molecules and cytokines. Front. Pharmacol. 3, 120 (2012).

20. Herold-Mende, C. et al. Clinical impact and functional aspects of tenascin-C expression during glioma progression. Int. J. Cancer 98, 362-369 (2002).

21. Xia, S. et al. Tumor microenvironment tenascin- $C$ promotes glioblastoma invasion and negatively regulates tumor proliferation. Neuro-Oncol. 18 507-517 (2016)

22. Sarkar, $\mathrm{S}$. et al. Activation of NOTCH signaling by tenascin-C promotes growth of human brain tumor-initiating cells. Cancer Res. 77, 3231-3243 (2017).

23. Kobayashi, $Y$. et al. Tenascin-C promotes angiogenesis in fibrovascular membranes in eyes with proliferative diabetic retinopathy. Mol. Vis. 22, 436-445 (2016).

24. Liang, $X$. et al. Rictor regulates the vasculogenic mimicry of melanoma via the AKT-MMP-2/9 pathway. J. Cell. Mol. Med. 21, 3579-3591 (2017).

25. Sun, Z. et al. Tenascin-C increases lung metastasis by impacting blood vessel invasions. Matrix Biol. https://doi.org/10.1016/j.matbio.2019.07.001 (2019).

26. Meng, J. et al. Hsp90ß promotes aggressive vasculogenic mimicry via epithelial-mesenchymal transition in hepatocellular carcinoma. Oncogene. https://doi.org/10.1038/s41388-018-0428-4 (2018). 
27. Mao, X. G. et al. CDH5 is specifically activated in glioblastoma stemlike cells and contributes to vasculogenic mimicry induced by hypoxia. Neuro-Oncol. 15, 865-879 (2013).

28. $\mathrm{Wu}, \mathrm{H}$. B. et al. Autophagy-induced KDRNEGFR-2 activation promotes the formation of vasculogenic mimicry by glioma stem cells. Autophagy 13, 1528-1542 (2017).

29. Eskilsson, E. et al. EGFRvIII mutations can emerge as late and heterogenous events in glioblastoma development and promote angiogenesis through Src activation. Neuro-Oncol. 18, 1644-1655 (2016).

30. Plate, K. H., Scholz, A. \& Dumont, D. J. Tumor angiogenesis and anti-angiogenic therapy in malignant gliomas revisited. Acta Neuropathol. 124, 763-775 (2012).

31. $\mathrm{Xu}, \mathrm{Y}$. et al. Short-term anti-vascular endothelial growth factor treatment elicits vasculogenic mimicry formation of tumors to accelerate metastasis. J. Exp. Clin. Cancer Res.: CR 31, 16 (2012).
32. Sun, J. et al. HMGA2 promotes vasculogenic mimicry and tumor aggressiveness by upregulating Twist 1 in gastric carcinoma. Sci. Rep. 7, 2229 (2017).

33. Yang, J. et al. HIF-2alpha promotes the formation of vasculogenic mimicry in pancreatic cancer by regulating the binding of Twist1 to the VE-cadherin promoter. Oncotarget 8, 47801-47815 (2017).

34. $\mathrm{Fu}$, J. et al. TGM2 inhibition attenuates ID1 expression in CD44-high gliomainitiating cells. Neuro-Oncol. 15, 1353-1365 (2013).

35. Shen, D. et al. Interferon-alpha/beta enhances temozolomide activity against MGMT-positive glioma stem-like cells. Oncol. Rep. 34, 2715-2721 (2015).

36. Feng, H. B. et al. $\beta$-Elemene selectively inhibits the proliferation of glioma stem-like cells through the downregulation of Notch1. Stem Cells Transl. Med. 6, 830-839 (2017). 